\title{
A LEI GERAL DE PROTEÇÃO DE DADOS COMO INSTRUMENTO DE CONCRETIZAÇÃO DA AUTONOMIA PRIVADA EM UM MUNDO CADA VEZ MAIS TECNOLÓGICO
}

\section{THE GENERAL LAW ON DATA PROTECTION AS AN INSTRUMENT FOR ACHIEVING PRIVATE AUTONOMY IN AN INCREASINGLY TECHNOLOGICAL WORLD}

\section{LUCAS GONÇALVES DA SILVA}

Pós-doutor em Direito pela Universidade Federal da Bahia e pela Università Degli Studi G. d'Annunzio (Itália). Doutor e Mestre em Direito do Estado pela Pontifícia Universidade Católica de São Paulo PUC/SP. Professor Associado da Graduação em Direito e do Programa de Mestrado em Direito da Universidade Federal de Sergipe. Vice-Presidente do Conselho Nacional de Pesquisa e Pós-Graduação em Direito CONPEDI.

\section{BRICIO LUIS DA ANUNCIAÇÃO MELO} Mestre em Direito pela Universidade Federal de Sergipe. Pós-Graduado em Direito Tributário pela Universidade do Sul de Santa Catarina. Professor Convidado da PósGraduação da Faculdade Estácio de Sergipe. Oficial de Justiça Avaliador Federal.

GUSTAVO KFOURI Investigador, membro dos grupos de pesquisa Cidadania Empresarial no Século XXI Unicuritiba - Brasil, e integrante do grupo de Pesquisa Internacional - REDTH(Rede de Estudos em Direitos Huamanos e Transnacionalidade). 


\section{RESUMO}

No mundo tecnológico, informações pessoais encontram-se dispersas em diversos bancos de dados. A privacidade passou a ser concebida como direito fundamental à autodeterminação informativa, deferindo-se ao indivíduo o controle de seus dados pessoais. Os bancos de dados vulneram a dignidade dos indivíduos, uma vez que há a sua completa exposição e é possível criar um perfil com base em informações que 
antes permaneciam dispersas. Com base na autonomia privada, a Lei Geral de Proteção de Dados passou a condicionar à anuência do titular a utilização de dados pessoais. Far-se-á uso da técnica de revisão de literatura sobre proteção de dados.

PALAVRAS-CHAVE: Autonomia privada; Autodeterminação informativa; Privacidade; Bancos de Dados; Dignidade da pessoa humana.

\section{ABSTRACT}

In the technological world, personal information is scattered across multiple databases. Privacy was conceived as a fundamental right to informational self-determination, allowing the individual to control their personal data. Databases violate the dignity of individuals, since there is complete exposure and it is possible to create a profile based on information that previously remained scattered. Based on the private autonomy, the General Law of Data Protection became conditioned to the consent of the holder the use of personal data. The literature review technique on data protection will be used.

KEYWORDS: Private autonomy; Informative self-determination; Privacy; Databases; Dignity of human person.

\section{INTRODUÇÃO}

Vivemos em um mundo extremamente tecnológico em que nossas informações pessoais encontram-se dispersas em diversos bancos de dados, que vão de cadastros públicos a registros pessoais em lojas de departamento. Para acessar o rede wifi de um determinado estabelecimento, temos que preencher formulários que revelam não apenas quem nós somos, mas, por meio das informações prestadas, torna-se possível criar um perfil do consumidor. Perfil este que pode ser, mais adiante, 
vendido para outras redes também interessadas, dentre inúmeras outras possibilidades.

Diante desse quadro, constata-se que, muito embora se reconheça a privacidade como direito da personalidade, esse direito não vinha sendo adequadamente respeitado, especialmente como um direito à autodeterminação informativa, no que tange à existência de bancos de dados e utilização de informações pessoais sem o consentimento de seu titular.

O presente texto tem por escopo demonstrar que a circulação de dados pessoais, especialmente diante nas novas tecnologias, somente pode ocorrer com 0 consentimento do indivíduo. Isso decorre do valor dignidade da pessoa humana de nossa Constituição Federal e passa a ser concretizado em nosso ordenamento jurídico com a promulgação da Lei 13.709/2018.

Com tal desiderato, far-se-á uma análise acerca da problemática dos bancos de dados em uma sociedade extremamente tecnológica como a nossa, uma vez que indivíduos são completamente expostos e se revela possível criar um perfil com base em informações que antes permaneciam dispersas. Com base na dignidade da pessoa humana, sustentar-se-á que a privacidade, antes concebida como um direito de resguardo contra interferências de terceiros, passa a ser concebida como um direito à autodeterminação informativa.

Com lastro nesse marco teórico, defender-se-á que o indivíduo passa a ser titular de um direito ao consentimento quanto à circulação de seus dados pessoais, reconhecendo-se ser uma violação à dignidade da pessoa humana a utilização de suas informações pessoais sem a sua anuência, em atenção à autonomia privada.

Para o atingimento desse fim, far-se-á amplo uso da técnica de revisão de literatura sobre direito à privacidade e autonomia privada, notadamente por ser um trabalho com questionamentos jurídicos. Por outro lado, serão invocados alguns aspectos do método histórico, de modo a localizar acontecimentos cujos desdobramentos auxiliam a compreensão do estado atual da proteção de dados pessoais no direito brasileiro. 


\section{OS BANCOS DE DADOS}

Um dos maiores problemas da privacidade na sociedade contemporânea e tecnológica é a criação de banco de dados. As informações pessoais são coletadas em diversas fontes e, quando reunidas em um único sistema, passam a fornecer um completo perfil da pessoa, que se vê completamente vulnerável perante bancos, agentes financeiros ou governamentais. Na sociedade de massas, a velocidade do fluxo de informações eleva a importância da proteção dos direitos da personalidade, especialmente da privacidade (SILVA; CARVALHO, 2017, p. 10)

A grande questão dos bancos de dados é que várias informações aparentemente pouco importantes da pessoa são coletadas como, por exemplo, seu perfil de compras, valores despendidos no supermercado, dentre tantos outros. Assim, esses dados que pouco dizem a respeito do indivíduo são armazenados e sistematizados, passando a fornecer um perfil minucioso do cidadão.

É em função disso que a proteção dos dados pessoais passou a ser encarada por meio de uma ótica mais abrangente, pela qual outros interesses devem ser considerados, compreendendo as diversas formas de controle tornadas possíveis com a manipulação de dados pessoais (DONEDA, 2006, p. 204).

A problemática relacionada aos bancos de dados e o direito à privacidade do cidadão já era enfrentada por nossos Tribunais já em 1995, quando a sociedade em rede ${ }^{1}$ ainda estava em formação. Nesse sentido, trago trecho de voto do Ministro Ruy Rosado de Aguiar que muito bem demonstra a preocupação com a manipulação de dados pessoais:

A inserção de dados pessoais do cidadão em bancos de informações tem se constituído em uma das preocupações do Estado moderno, onde o uso da informática e a possibilidade de controle unificado das diversas atividades da

\footnotetext{
${ }_{1}^{1}$ Para Manuel Castells, a sociedade que vivenciamos hoje não mais seria a de informação, mas a de rede. Segundo o referido autor, a atual revolução tecnológica acarretou não a centralidade do conhecimento e das informações, mas sim novas formas de comunicação, baseadas na internet, às quais ele denomina de autocomunicação de massas. Essa nova forma de comunicação, que tem sua espinha dorsal formada por redes de computadores, alcança uma audiência global e possibilita uma diversidade e autonomia ilimitadas no fluxo de comunicação que constroem significado na cabeça das pessoas. (CASTELLS, 2016, p. 23).
} 


\begin{abstract}
pessoa, nas múltiplas situações de vida, permitem o conhecimento de sua conduta pública e privada, até nos mínimos detalhes, podendo chegar à devassa de atos pessoais, invadindo área que deveria ficar restrita à sua intimidade (...). E assim como o conjunto dessas informações pode ser usado para fins lícitos, públicos e privados, na prevenção ou repressão de delitos, ou habilitando o particular a celebrar contratos com pleno conhecimento de causa, também pode servir, ao Estado ou ao particular, para alcançar fins contrários à moral ou ao Direito, como instrumento de perseguição política ou opressão econômica. (BRASIL, STJ, 1995).
\end{abstract}

Nesse sentido, a doutrina defende que o enorme aumento de quantidade de informações pessoais coletadas por instituições públicas e privadas, as quais alimentam os diversos bancos de dados, visa a dois objetivos específicos. Por primeiro, a aquisição dos elementos necessários à preparação e gestão de programas de intervenção social, bem como o controle da conformidade dos cidadãos à gestão política dominante. Intenta-se, ainda, no aspecto privado, a obtenção de informações necessárias para o desenvolvimento de estratégias empresariais (RODOTÀ, 2008, p. 28).

Como conseqüência dessa ampliação do alcance informacional dos bancos de dados, doutrinadores verificaram o surgimento de um verdadeiro corpo eletrônico, formado pelas nossas informações pessoais, que se contrapõe à própria realidade da pessoa, ao nosso corpo real. Esse nosso perfil virtual pode ser denominado de várias formas como corpo digital, avatar ou pessoa virtual. É o que, com precisão, Pierre Lévy conceitua como "hipercorpo" híbrido, social e tecnobiológico:

O meu corpo pessoal é a manifestação temporária de um enorme "hipercorpo" híbrido, social e tecnobiológico. O corpo contemporâneo se assemelha a uma chama. Ele costuma ser minúsculo, isolado, separado, quase imóvel. Depois, ele chega a fugir de si mesmo, intensificado pelos esportes ou pelas drogas, passa através de um satélite, lança algum braço virtual em direção ao céu, ao longo das redes de interesses ou de comunicação. (LÉVY, 1996, p. 17-18).

Outra construção doutrinária que denota a quantidade de informações pessoais armazenadas em bancos de dados é o data shadow. Alan Westin cunhou esse termo - sombra de informações - para identificar os dados pessoais 
armazenados e que acompanham o indivíduo, como uma sombra, aonde quer que ele vá (DONEDA, 2006, p. 175).

No que tange a essa expressão, cabe ressaltar que ela foi um pouco condescendente com a realidade que presenciamos. Ora, não podemos afirmar que nossos dados sistematizados em bancos são uma sombra - uma vez que sempre visível - porque, na maior parte dos casos, o indivíduo não sabe, sequer, que suas informações pessoais foram colhidas e estão à disposição de órgãos de controle ou de entidades privadas.

Quanto ao tema de proteção de informações pessoais em sede de banco de dados, Catarina Sarmento e Castro (2002, p. 478) defende, em função da importância para a economia dos chamados ficheiros de crédito ${ }^{2}$, que seja encontrado um equilíbrio entre a garantia das liberdades e direitos individuais e a liberdade de utilização e circulação de informações necessárias às relações empresariais. Entretanto, ela (2002, p. 511) ressalva que, mesmo em sede de bancos de dados de consumidores, apenas o respeito aos princípios fundamentais de proteção das informações pessoais permitirá salvaguardar 0 núcleo essencial do direito fundamental à autodeterminação informativa ${ }^{3}$.

Dessa forma, a proteção dos dados pessoais, especialmente no que tange à possibilidade de sua utilização em bancos de dados, atingiu outro patamar, modificando seus elementos, aprofundando postulados, de modo a proteger a privacidade do indivíduo. É por isso que o professor Rodotà defende um amplo controle de quaisquer tipos de dados pessoais por seu titular, como será explicitado no item 4. Assim, na sociedade de informação4 ou de rede, o titular tem o direito de

\footnotetext{
2 São os bancos de dados de consumidores e maus pagadores utilizados e criados por agentes financeiros em Portugal.

${ }^{3}$ Para a doutrinadora portuguesa, o direito à autodeterminação informativa seria autônomo ao direito à privacidade.

${ }^{4}$ Sociedade da Informação é um termo que surgiu no século XX, no momento em que a tecnologia teve grandes avanços. O conceito surgiu nos trabalhos de Alain Touraine (1969) e Daniel Bell (1973) sobre as influências dos avanços tecnológicos nas relações de poder, identificando a informação como ponto central da sociedade contemporânea. As sociedades contemporâneas são, assim, atravessadas por inúmeras mudanças, sendo relevante a que se prende com as novas tecnologias. Estas não transformam a sociedade por si só, mas são utilizadas pelas pessoas em seus contextos sociais, econômicos e políticos, criando uma nova comunidade local e global: a Sociedade da Informação. (GOUVEIA, 2004, p. 1).
} 
não apenas conhecer, mas também de controlar e interromper o fluxo de dados a ele relacionados (RODOTÀ, 2008, p. 92).

Diante desse quadro de apropriação de dados pessoais, surgem diversos riscos políticos ligados aos registros em massa da população em geral, na medida em que há a possibilidade de discriminação real de diferentes minorias, que vêem suas informações pessoais completamente expostas, bem como daqueles que pertencem à classe trabalhadora.

\section{A PRIVACIDADE COMO AUTODETERMINAÇÃO INFORMATIVA}

Ainda nos anos 80, a doutrina asseverava que a revolução tecnológica teria aberto um universo em que a criatura humana teria perdido a individualidade. Os cidadãos estariam sujeitos à vigilância constantemente, de modo que não haveria segredos para o Governo (DOTTI, 1980, p. 142).

Stefano Rodotà sustenta que viveríamos em uma esquizofrenia social, política e institucional pois, malgrado tenha aumentado a consciência da importância de proteção de dados, cada vez mais é difícil respeitar a privacidade dos indivíduos, "uma vez que as exigências de segurança interna e internacional, interesses de mercado e a reorganização da administração pública estão levando à diminuição de salvaguardas importantes, ou ao desaparecimento de garantias essenciais" (RODOTÀ, 2008, p.13).

Assim, podemos constatar que nos encontramos em um estado de vigilância líquida, na medida em que o controle suaviza-se, especialmente, na questão do consumo. Desse modo, a proteção à privacidade se afrouxaria à medida que fragmentos de dados pessoais obtidos com uma finalidade seriam, facilmente, utilizados com diverso fim (BAUMAN; LYON, 2013, p.10).

O que distingue a informação pessoal e sua importância para os dias de hoje é que vivemos em uma sociedade de informação ou de rede, consoante já asseverado. As informações, antes dispersas em inúmeros bancos de dados, com a 
tecnologia hoje existente, passaram a ser reunidas e, portanto, passíveis de utilização e apropriação. Desse modo, há uma "maior desenvoltura na sua manipulação, desde a coleta e tratamento, até os meios para sua comunicação. $O$ vetor que faz a diferença é exatamente o tecnológico" (DONEDA, 2006, p. 153).

Com efeito, José Adércio Sampaio entende que as inovações tecnológicas no campo da informática quanto ao tratamento de dados pessoais acabaram por redefinir o conceito de privacidade (SAMPAIO, 1998, p. 496). E isso se deu pois, na sociedade de vigilância em que se vive, a informática acabou por transformar o cidadão em um homem de vidro: totalmente exposto em função da ampla circulação sem controle de seus dados pessoais (RODOTÀ, 2008, p.8).

Destarte, nossas informações pessoais possuem um vínculo por demais estreito com nós mesmos e, assim, acabam por nos revelar a quem as possuir. Essa é a razão primordial da tutela dos dados pessoais pois, ao ter informações sobre as pessoas, torna-se possível não apenas conhecê-las, mas criar um perfil com base em informações que, antes espalhadas, passam a se encontrar reunidas. Nesse sentido, podemos concordar com Pierre Catala (1998, p. 231-232) ao afirmar que a informação pessoal, ao revelar um sujeito de direito mediante seus dados, é um atributo da personalidade.

E essa vinculação entre pessoa e informação pessoal foi corroborada na Convenção de Estrasburgo de 1981 para o tratamento de dados pessoais ao conceituar, no artigo 2 - a, dados pessoais como "qualquer informação relativa a uma pessoa singular identificada ou suscetível de identificação" (CONSELHO DA EUROPA, 1981). Assim, pode-se entender uma informação ou dado como pessoal quando ela estiver vinculada a uma determinada pessoa, podendo revelar algum aspecto da mesma.

A doutrina nacional também perfilha esse entendimento, ao sustentar que a informação pessoal deve ser entendida como uma extensão da personalidade do indivíduo e, como tal, deve ser protegida pelo Direito. Haveria, portanto, uma representação direta da personalidade que decorreria da vinculação entre a informação pessoal e a pessoa a qual ela se refere (DONENA, 2006, p. 168). 
Reconhecida a importância dos dados pessoais para a tutela da privacidade, há de se perquirir como houve a mudança de paradigma na proteção de tal direito fundamental. Cabe analisar como e em que medida a privacidade passou a ser encarada como proteção de dados pessoais, ainda que tais informações não sejam dotadas de sigilo, e sim dados comuns que revelam a personalidade do indivíduo.

Havia doutrinadores, como Allan Westin, que já afirmavam ser a privacidade o direito a controlar a maneira na qual os outros utilizariam as informações a nosso respeito. Entretanto, foi com uma célebre sentença do Tribunal Constitucional Alemão, em 1983, que, ao julgar uma lei do censo ${ }^{5}$ aprovada no ano anterior, utilizou a expressão "autodeterminação informativa" ${ }^{6}$ para designar o direito dos indivíduos de decidirem por si sós, quando e dentro de quais limites seus dados pessoais podem ser utilizados (DONEDA, 2006, p. 196).

Nessa sentença, consolidou-se o entendimento que não se pode apenas levar em conta o tipo de informações, uma vez que tais dados podem ser combinados com outros e fornecer o perfil do indivíduo. Com isso, um dado em si insignificante pode adquirir um novo valor, de modo que não existem mais dados "insignificantes" no contexto do processamento eletrônico de dados (MARTINS, 2005, p. 239).

Assim, o direito à autodeterminação informativa é uma afirmação do personalismo e proporciona à pessoa o controle de suas informações. Aquele clássico direito à privacidade de não intromissão foi transformado no direito à autodeterminação informativa, o qual assegura ao titular o controle de suas informações, tanto em um aspecto negativo, como positivo (SAMPAIO, 1998, p. 495).

Essa faceta positiva cuida do direito do homem de controlar suas informações pessoais, não apenas impedindo a sua utilização, como também tendo o controle das informações constantes em arquivos públicos e privados (ECHTERHOFF, 2010, p 152).

\footnotetext{
${ }^{5}$ Essa lei (Volkszahlungsgesetz) previa que os dados colhidos seriam não apenas confrontados com os dados do registro civil,mas também a possibilidade de transferência dos mesmos para outras autoridades federais. Era prevista, ainda, uma multa para os cidadãos que não fornecessem as informações, bem como um mecanismo de favorecimento para quem denunciasse aqueles que se omitiram a responder o questionário. (MARTINS, 2005, p. 234).

${ }^{6}$ Informationelle Selbstbestimmung.
} 
Pode-se, então, entender que o direito à privacidade, diante dessa face positiva da autodeterminação informativa, seria, qualitativamente, diferente da privacidade tal como concebida como um direito de estar só. Percebe-se um ponto de chegada na longa evolução do conceito de privacidade: o direito de controle sobre as próprias informações e determinar construção da própria esfera privada (RODOTÀ, 2008, p. 7).

De fato, reconhecer que o homem é livre acarreta conferir a ele a possibilidade de controle sobre as informações que a ele digam respeito. Assim, para José Adércio, o que o Tribunal Constitucional Alemão fez foi reconhecer um direito de liberdade informacional ao indivíduo, o qual não afasta o direito clássico de privacidade com viés negativo (SAMPAIO, 1998, p. 363).

Nesse sentido, a inviolabilidade da vida privada prevista no artigo 21 do Código Civil, em uma evidente leitura abstencionista acerca do direito à privacidade, deve ser encarada também no aspecto positivo, em uma função promocional e de controle de privacidade, mormente em uma sociedade tecnológica em que os dados dos cidadãos circulam livremente e sem qualquer controle.

Ressalte-se, então, que aquele aspecto clássico ainda persiste, diante da necessidade de não tornar público certos acontecimentos ou comportamentos. Além desse aspecto, garante-se o direito de o indivíduo ter pleno controle de suas informações pessoais constantes em bancos de dados, sendo-lhe assegurada a escolha das informações a serem armazenadas, bem como sua retificação ou cancelamento (ECHTERHOFF, 2010, p 155).

Essa evolução conceitual dos direitos da personalidade, especialmente do direito à privacidade, foi observada através da construção de uma sociedade cada vez mais informatizada e comprometida com a dignidade da pessoa humana. Com isso, novos aspectos de direitos da personalidade, como a autodeterminação informativa, foram construídos pela dinamização das relações enfrentadas pelos indivíduos na sociedade da informação (SILVA; CARVALHO, 2017, p. 9).

Ainda quanto ao tema, Stefano Rodotà, ao comentar o artigo 8 da Carta dos Direitos Fundamentais da União Européia, que prevê, expressamente, a proteção dos 
dados como um direito à autodeterminação informativa, sustenta que a proteção das informações pessoais seria um tipo de proteção dinâmica, em contraposição à proteção estática ou negativa da vida familiar, prevista no artigo $7^{\circ}$. Assim, os dados pessoais devem ser protegidos em todos os seus movimentos, desde a informação de per si, até o fluxo de dados em dinâmica (RODOTÀ, 2008, p. 17).

Acrescenta-se a esse fato considerar o cidadão como portador de uma autonomia informacional, como já asseverado, não sendo mais possível considerá-lo um mero fornecedor de dados, sem que a ele caiba alguma espécie de controle. Entretanto, surge um questionamento: como se dará esse controle amplo de generalizado?

\section{O CONTROLE DAS INFORMAÇÕES PESSOAIS}

Explicitada a necessidade de tutela dos dados pessoais, cabe, agora, distinguir as espécies de informações pessoais, bem como aferir se quaisquer tipos de informação são aptas a serem controladas pelos seus titulares.

Nesse sentido, informação pessoal seria aquele dado relacionado a um indivíduo identificado ou identificável, independentemente do suporte em que se encontre registrado, incluindo escrita, imagem, som ou vídeo (CASTRO, 2002, p. 481). Assim, identificado é aquele indivíduo que já é conhecido e identificável a pessoa que pode ser conhecida diretamente pelo possuidor de seus dados ou, indiretamente, por meio de recursos à disposição de terceiros.

Para Marcel Leonardi, seria amplo demais e escaparia da tutela da privacidade o controle de todas as informações pessoais. Ele afirma que haveria uma grande quantidade de informações que identificam uma pessoa, mas existem muitas delas que não seriam privadas. Para ele, o essencial seria a defesa da personalidade (LEONARDI, 2009, p. 76).

Isto posto, cabe destacar que as informações pessoais podem ser nominativas, quando referentes a uma pessoa determinada, e não nominativas, que 
são os dados não relacionados ou identificados a pessoas determinadas e que podem ser objeto de apropriação sem qualquer tipo de restrição. Excepcionam-se algumas limitações decorrentes de regimes legais específicos, como no caso das normas protetivas da propriedade intelectual, as quais impedem que, sem autorização do autor, terceiros tenham acesso a dados específicos.

Como exemplos de dados não nominativos, a doutrina menciona os "dados estatísticos, bibliográficos, econômicos, sociais, políticos e eleitorais não relacionados ou identificados - pelo menos diretamente - com alguma pessoa" (REINALDO FILHO, 2006, p. 99). Nesse sentido, por serem dados anônimos, referentes a uma coletividade (DONEDA, 2006, p. 158), sua apropriação, uso ou difusão não atingiriam os direitos da personalidade na medida em que não atingiriam a privacidade do indivíduo (REINALDO FILHO, 2006, p.99)

Já em relação aos dados nominativos, estes se subdividem em dados sensíveis e não-sensíveis, os quais seriam aqueles não reservados ao seu titular. Como exemplos, mencionam-se "dados que se referem a atributos da pessoa (como nome, estado civil e domicílio) ou a qualquer outra circunstância de sua vida civil e profissional (como profissão, ocupação educação, filiação a grupos associativos, etc)" (REINALDO FILHO, 2006, p. 97).

Tais dados não geram danos ou risco de dano ao seu titular. Desse modo, podem ser utilizados e armazenados, reservando-se ao titular o controle de sua existência, veracidade e possibilidade de retificação (ECHTERHOFF, 2010, p. 157). Confere-se ao indivíduo esse direito ao controle e retificação de tais dados, pois o decurso do tempo pode gerar alterações nos mesmos que podem gerar danos, como se vislumbra na hipótese de um banco de dados desatualizado em que a correspondência não chegue ao destinatário.

Já os dados sensíveis são aqueles ligados diretamente à privacidade do indivíduo e que, se utilizadas, podem acarretar utilização discriminatória ou lesiva ao titular (DONEDA, 2006, p. 160). Como exemplos, mencionam-se as preferências sexuais da pessoa, as condições de sua saúde, sua adesão a idéias políticas, ideologias, crenças religiosas, bem como suas manias, trações do seu caráter e 
personalidade (REINALDO FILHO, 2006, p. 98). Dessa forma, gozam de maior proteção jurídica, de modo que o titular pode, além de controlar seu armazenamento, uso e veracidade, impedir totalmente sua utilização (ECHTERHOFF, 2010, p. 157).

Em oposição a essa tutela primordial apenas dos dados sensíveis, existem doutrinadores que, considerando a sociedade em rede hoje existente e todos os problemas da privacidade já mencionados, indicam a existência de um profundo processo de revisão dos critérios de classificação das informações pessoais. Haveria a necessidade de aplicação de uma escala de valores renovada, de modo a conferir "o máximo de opacidade às informações suscetíveis de originar práticas discriminatórias (RODOTÀ, 2008, p. 35).

Diante dessa nova necessidade, as técnicas tradicionais seriam insuficientes. Não haveria como distinguir um possível núcleo "duro" da privacidade, passível de proteção e pleno controle por parte do titular da informação, com diverso tratamento quanto aos demais dados. Nessa sociedade de informação, revela-se cada vez mais difícil individualizar os tipos de dados em que o cidadão poderia renunciar a qualquer espécie de controle. $E$ isso ocorre pelo motivo de que até as informações aparentemente inócuas, se devidamente integradas a outras, podem provocar danos ao indivíduo.

Acrescenta-se a esse fato considerar o cidadão como portador de uma autonomia informacional, como já asseverado, não sendo mais possível considerá-lo um mero fornecedor de dados, sem que a ele caiba alguma espécie de controle. Entretanto, surge um questionamento: como se dará esse controle amplo de generalizado?

Para Stefano Rodotà esse amplo controle em quaisquer dados pessoais se revela como um instrumento de equilíbrio na nova distribuição de poder que estaria se delineado na sociedade, uma vez que a privacidade deve hoje ser compreendida como tendo passado da fase do sigilo ao controle. Esse controle, para o referido autor, além de individual se dilata na dimensão coletiva (RODOTÀ, 2008, p. 36-37).

Essa, portanto, é uma visão extremamente garantista uma vez que confere uma plena eficácia ao direito da privacidade. Cabe ressaltar que essa visão teve 
acolhida na recente lei 13.709/2018, Lei Geral de Proteção de Dados, que dispõe sobre a proteção de dados pessoais no direito brasileiro. Essa lei condicionou a utilização de informações pessoais não sensíveis, como nome, telefone, endereço e CPF ao consentimento de seu titular ${ }^{7}$, bem como assegurou a possibilidade de anotação e exclusão.

O que se pode extrair de importante neste momento, em que a promulgação ainda é bastante recente, é que se há a determinação legislativa para o consentimento quanto ao uso e armazenamento de dados pessoais, ainda mais importante é a anuência do interessado para o tratamento de dados sensíveis. Nesse sentido, o próprio projeto de lei aprovado prevê o consentimento ${ }^{8}$ para a utilização de dados sensíveis do indivíduo.

A Carta dos Direitos Fundamentais da União Européia foi precisa ao captar essa mudança de paradigma no âmbito de proteção do direito à privacidade, ao desdobrar ${ }^{\circ} \mathrm{O}$ direito da personalidade em duas partes: $\mathrm{o}$ respeito à vida familiar $\mathrm{e}$ privada e a proteção dos dados pessoais. Assim, sem que tivesse sido "fragmentada sua fundamentação, que é a dignidade do ser humano" (DONEDA, 2006, p. 27), a Carta conferiu ao povo europeu uma proteção à privacidade de uma maneira completa e atual, compatibilizando a vedação de intromissões exteriores à tutela de dados pessoais, por meio do consentimento, que é a nova e contemporânea faceta desse direito da personalidade.

Baseado nesse exemplo europeu, o Brasil, com a promulgação da lei de dados pessoais, passou entender se a privacidade "o direito de manter o controle sobre as próprias informações e de determinar as modalidades de construção da

\footnotetext{
${ }^{7}$ Artigo 7을 Lei 13.709/2018. O tratamento de dados pessoais somente poderá ser realizado nas seguintes hipóteses:I -mediante o fornecimento de consentimento pelo titular.

${ }^{8}$ Artigo 11, Lei 13.709/2018. É vedado o tratamento de dados pessoais sensíveis, exceto:I - com fornecimento de consentimento específico e em destaque, pelo titular, para finalidades específicas.

${ }^{9}$ Artigo 7ํㅡ. Carta dos Direitos Fundamentais da União Européia. Todas as pessoas têm direito ao respeito pela sua vida privada e familiar, pelo seu domicílio e pelas suas comunicações.

Artigo $8^{\circ}$, Carta dos Direitos Fundamentais da União Européia. 1.Todas as pessoas têm direito à proteção dos dados de caráter pessoal que lhes digam respeito.2. Esses dados devem ser objeto de um tratamento leal, para fins específicos e com o consentimento da pessoa interessada ou com outro fundamento legítimo previsto por lei. Todas as pessoas têm o direito de acessar os dados coligidos que Ihes digam respeito e de obter a respectiva retificação.3.O cumprimento destas regras fica sujeito a fiscalização por parte de uma autoridade independente.
} 
própria esfera privada" (RODOTÀ, 2008, p. 92). Essa forma de entender a privacidade revela-se consentânea com o mundo em que vivemos pois entende ser ela meio para o livre desenvolvimento da personalidade, ao conferir ao indivíduo primazia e controle sobre sua vida privada e informações pessoais.

\section{A LEI GERAL DE PROTEÇÃO DE DADOS COMO INSTRUMENTO DE CONCRETIZAÇÃO DA AUTONOMIA PRIVADA}

O papel desempenhado pela vontade é de fundamental importância não apenas para o Direito Civil mas para todo o Direito. No entanto, muito embora se reconheça a importância da vontade para o Direito, esta não pode ser analisada fora do contexto social. Do contrário, estar-se-ia aplicando um verdadeiro dogma acerca da vontade.

Nessa perspectiva eminentemente individualista, a pessoa se obrigaria tãosomente através da declaração de vontade, deixando-se em outro plano a análise de outras circunstâncias nas quais o negócio jurídico deveria ser examinado. Assim, uma vez manifestada a vontade, haveria suficiência, por si só, para gerar conseqüências jurídicas.

A essa concepção extremamente liberal e individualista, que conferia força à vontade, independentemente da análise do contexto em que proferida, a doutrina denominou de autonomia da vontade ${ }^{10}$. Cabe, ainda, destacar que ela difere, profundamente, do conceito de liberdade jurídica, não significando a faculdade de atuar licitamente para o Direito (BORGES, 2007, p. 47).

Com o passar do tempo e uma crescente valorização da pessoa humana, o conceito de autonomia de vontade evoluiu para uma concepção de autonomia privada, mais vinculada aos valores constitucionais. No entanto, cabe ressaltar que, embora a

\footnotetext{
${ }^{10}$ Curioso notar que a expressão autonomia da vontade foi criada por Emmanuel Gounot como crítica às idéias liberais e individualistas, quando elaborou a tese Le príncipe de l'autonomie de la volonté em droit prive: contribution à l'étude critique de l'individualisme. (NAVES, 2014, p. 95).
} 
teoria da autonomia da vontade tenha sido superada pela autonomia privada, muitos autores ainda seguem utilizando a anterior terminologia (BORGES, 2007, p. 51).

Superada a concepção que concedia força absoluta à vontade em detrimento do ordenamento jurídico, coube ao Direito analisar a manifestação concreta da vontade, segundo critérios objetivos de boa-fé, e não suas causas e características intrínsecas. Passou-se a aferir a vontade dentro do contexto em que manifestada, mas não a ponto de se perquirir quanto ao conteúdo da consciência interna de cada indivíduo (NAVES, 2014, p. 94).

Assim, a teoria da autonomia privada superou o dogma absoluto da vontade, ao sustentar que o puro consenso não seria capaz de criar o direito. Apenas o consentimento que for compatível com o ordenamento, de modo que este confira legitimidade ao acordo de vontade, pode ser aceito.

Haveria dois âmbitos distintos de competência jurídica: o âmbito particular, individual, da autonomia privada, e o âmbito público, soberano, de competência normativa estatal. A manifestação de vontade, dessa forma, isoladamente, não teria valor jurídico, como fazia crer o voluntarismo ${ }^{11}$. Só o terá se estiver de acordo com a Constituição, as leis, a ordem pública, à moral e os bons costumes (BORGES, 2007, p. 54)

Neste particular, a idéia de inseparabilidade entre pessoa e sua vontade foi essencial para a consolidação do consensualismo ${ }^{12}$, em oposição à teoria do voluntarismo. Segundo Irineu Strenger, a vontade passou a ser encarada como centro da vida da pessoa, como a própria expressão psíquica do indivíduo (2000, p. 23). A vontade, em um ato ou negócio jurídico, reflete "a tomada de consciência de si mesmo, que possibilita ao homem encontrar-se existencialmente numa situação" (STRENGER, 2000, p. 24).

\footnotetext{
11 Para o voluntarismo, é a declaração de vontade que gera atos e negócios jurídicos, tendo parte da doutrina chegado a considerar a vontade como fonte de direitos. (BORGES, 2007, p. 52).

12 Para o consensualismo, o poder de gerar regras jurídicas não está na simples vontade da pessoa, mas na declaração de vontade que estiver autorizada pelo ordenamento jurídico, quanto à forma, quanto ao conteúdo, e quanto á capacidade e legitimidade do sujeito. (BORGES, 2007, p. 54).
} 
A autonomia privada passa a ser encarada como atividade dos indivíduos como expressão da própria liberdade, autodeterminação, auto-regulamentação e poder da vontade, de acordo com o ordenamento. Cada um passa a ser o melhor juiz dos seus próprios interesses (PERLINGIERI, 2008, p. 339-340).

Nesse sentido, pode-se mencionar uma função dispositiva da autonomia privada, a qual se manifesta no campo das opções concedidas ao indivíduo, que pode realizar o ato jurídico da forma como achar conveniente, dentro do previsto pelo ordenamento jurídico. É por essa razão que Luigi Ferri, ao elaborar um tradicional estudo sobre autonomia privada, considera esta sinônimo de poder de disposição, de modo que ambas teriam o mesmo conteúdo (FERRI, 1959, p. 224).

Destarte, a autonomia privada é um dos fundamentos do Direito Privado, sendo os negócios jurídicos os instrumentos tradicionalmente apontados como meios, por excelência, para a realização ou materialização da mesma. No entanto, a autonomia privada não pode se restringir a negócios jurídicos patrimoniais.

Nesse sentido, Pietro Perlingieri assegura que a autonomia privada "se exprime também em matérias onde diretamente são envolvidas situações subjetivas existenciais (...) em que a abordagem do ordenamento não pode ser abstrata quando a autonomia investe profundamente o valor da pessoa" (2008, p. 348). Assim, atos de autonomia privada acontecem em diversas áreas e não apenas em âmbito econômico. Neste particular, cabe salientar que "o negócio jurídico é categoria mais ampla que o contrato e envolve manifestação de autonomia privada, seja ela de cunho patrimonial ou não" (BORGES, 2007, p. 50).

Com efeito, quando a negociação ocorre em sede de interesses não patrimoniais, normalmente se está diante de direitos da personalidade. Vemos expressões desse caráter dispositivo em diversas áreas, como cessão de uso de imagem, de voz, cessão de direitos da personalidade como em reality shows, dentre tantas outras.

Em tais situações, quando o poder de disposição atinge fortemente o valor da pessoa, Pietro Perlingieri destaca que a consideração do ordenamento não pode ser abstrata (2008, p. 349). Do contrário, estar-se-ia formalisticamente igualando 
manifestações de liberdade que tocam profundamente a identidade do indivíduo e liberdade de perseguir o maior lucro possível (quanto aos negócios jurídicos estritamente patrimoniais).

Dessa forma, o consentimento referente a direitos de personalidade é nitidamente diferente daquele realizado em situações puramente patrimoniais e, como tal, deve ser aferido com uma diferenciada valoração quanto à hierarquia dos valores constitucionais. Assim, a prevalência do valor conferido à pessoa humana pelo nosso ordenamento jurídico constitucional condiciona a interpretação de cada ato ou atividade para que seja realizada à luz da dignidade da pessoa humana.

Destarte, os negócios jurídicos não patrimoniais encontram seu limite no princípio fundamental da dignidade da pessoa humana. Nesses casos, não basta uma mera aquiescência, mas deve haver um devido consentimento informado. Isso porque os interesses em torno de tais negócios jurídicos devem estar dentro daqueles considerados legítimos pela sociedade e pela ordem constitucional vigente. A dignidade passa a ser limite dos negócios jurídicos não patrimoniais ao mesmo tempo em que se manifesta por meio da autonomia privada, sendo esta uma concretização daquela. Quanto a essa relação, Diego Luna Moureira é preciso:

\footnotetext{
A dignidade da pessoa humana se faz, portanto, pela exteriorização de uma realidade histórico-cultural que decorre do reconhecimento e da possibilidade normativa de assunção de uma pessoalidade, pelo exercício da autonomia privada. (MOUREIRA, 2001, p. 137).
}

No que tange ao consentimento, ele deve ser considerado livre quando for dado sem qualquer pressão e possa ser retirado sem restrições ou oposição. Não é livre o consentimento sem o qual o indivíduo sofra qualquer conseqüência (CASTRO, 2005, p. 207). Ademais, Catarina Sarmento e Castro sustenta, no que tange aos dados pessoais, que, para consentir, o titular do direito deve ser informado da finalidade e da extensão exata do seu consentimento, como possíveis destinatários dos dados informados e do responsável pelo tratamento dos dados, dentre outros fatores (2005, p. 207). 
Dessa forma, há a necessidade de consentimento da pessoa quanto ao fornecimento de dados pessoais sensíveis e não sensíveis, consoante explicitado na Lei Geral de Proteção de Dados, uma vez que nosso sistema constitucional não permite que se negligencie o sistema de direitos fundamentais (NAVES, 2014, p. 48). Reconhece-se o ser humano como ser dotado de subjetividade concreta e, dessa forma, proteger-Ihe a vontade e autonomia individual. É por essa razão que Bruno Torquato sustenta ser a aplicação da autonomia privada um instrumento de realização da personalidade (2014, p. VII). Nesse sentido, a doutrina é enfática:

[...] há que se traçar sempre limites a partir dos quais seja defeso ao Estado exercer diretamente seu poder de império. É a necessidade, fundada na própria dignidade da pessoa humana e na tutela do direito ao livre desenvolvimento da personalidade, do reconhecimento e proteção, pelo ordenamento jurídico, de um espaço irredutível de autonomia privada. (LUDWIG, 2002, p. 106).

E essa tutela ao livre desenvolvimento da personalidade, fundada no artigo $1^{\circ}$, III, da Constituição Federal tanto pode ocorrer de forma negativa, como de forma positiva. Assim, reconhece-se o exercício positivo dos direitos da personalidade fundado na autonomia privada (LUDWIG, 2002, p. 265).

A autonomia privada desponta, portanto, como o principal instrumento conferido ao indivíduo para o exercício positivo dos direitos de personalidade (BORGES, 2007, p. 106). Isso sem menoscabar a tutela negativa também desempenhada por ela, uma vez que, para ambas as tutelas, o exercício da liberdade individual é essencial.

Dessa forma, ao invés de se caracterizar uma renúncia de direito, o indivíduo pode, voluntariamente, consentir quanto ao fornecimento de dados pessoais, sem haver qualquer violação à liberdade individual a ele inerente, desde que seja um consentimento informado. Cabe recordar que a autonomia privada, como princípio jurídico, é norma jurídica que atribui aos indivíduos um poder. Impregnada de imperatividade, ela concede essa possibilidade de disposição, como solucionadora direta de problemas jurídicos (NAVES, 2014, p. 96). 
Dessa forma, o direito à privacidade de dados pessoais pode, sim, sofrer limitação. Mas essa restrição não pode ocorrer por força do imperativo Estatal que viola a autonomia individual, mas uma limitação voluntária por parte do titular do direito em questão. Como ressalta Roxana Borges, a irrenunciabilidade típica dos direitos de personalidade não afasta a possibilidade jurídica do consentimento do próprio indivíduo quanto à limitação voluntária ao exercício dos direitos da personalidade (BORGES, 2007, p. 124).

\section{CONCLUSÃO}

O entendimento de privacidade foi sendo alterado ao longo do tempo, tendo havido uma mudança de perspectiva para a tutela da dignidade humana, bem como uma adequação às novas exigências de proteção da esfera privada em um mundo moderno, diante de recentes tecnologias de informação. Assim, a privacidade passou a representar não apenas a proteção de questões existenciais das pessoas, como convicção política, ideologias ou religião, mas também passou a tutelar uma proteção aos dados pessoais.

Nesse sentido, privacidade, diante das inovações tecnológicas, é compreendida como direito fundamental à autodeterminação informativa, sendo imperioso compreender que a finalidade da proteção deste direito consiste na proteção da esfera privada, na busca da consagração da dignidade da pessoa humana.

Dessa forma, por meio da promulgação da Lei 13.709/2018 o Brasil passou a conferir primazia à autonomia privada no que tange à circulação de seus dados pessoais dos indivíduos. Por meio da recente legislação de proteção de informações pessoais, condicionou-se seu uso e armazenamento à autorização do interessado, de modo a se afirmar que o Brasil pôde, enfim, concretizar a privacidade como um direito à autodeterminação informativa. 
Assim, o titular do direito à privacidade, observando a autonomia privada que Ihe é inerente, pode autorizar e determinar limitações ao próprio direito que lhe assiste. Em um mundo cada vez mais tecnológico, em que todos estão sujeitos a vigilância constante, a privacidade passa a ser reconhecida em seu aspecto positivo de autodeterminação informativa. É o triunfo da autonomia privada que passa a ter aplicação no âmbito das informações pessoais.

\section{REFERÊNCIAS}

BAUMAN, Zygmunt; LYON, David. Vigilância líquida. Rio de Janeiro: Zahar, 2013. . Modernidade e ambivalência. Rio de Janeiro: Zahar, 1999.

BORGES, Roxana Cardoso Brasileiro. Direitos da personalidade e autonomia privada. 2. ed. São Paulo: Saraiva, 2007.

CASTELLS, Manuel. A sociedade em rede. São Paulo: Paz e Terra, 2016.

CASTRO, Catarina Sarmento e. Direito da informática, privacidade e dados pessoais. Coimbra: Almedina, 2005.

. O direito à autodeterminação informativa e os novos desafios gerados pelo direito à liberdade e à segurança no pós 11 de setembro. In: VIII CONGRESSO IBERO-AMERICANO DE DIREITO CONSTITUCIONAL, 2003, Sevilha. Anais eletrônicos. Disponível em: <http://egov.ufsc.br/portal/conteudo/o-direito-\%C3\%A0autodetermina\%C3\%A7\%C3\%A3o-informativa-e-os-novos-desafios-gerados-pelodireito-\%C3\%A0-liberda>. Acesso em: 18 jun. 2018.

. Os ficheiros de crédito e a proteção de dados pessoais. Boletim da Faculdade de Direito de Coimbra, n. 78, p. 475-511, 2002.

CATALA, Pierre. Ebauche d'une théorie juridique de l'information. In: Le droit à l'épreuve du numérique. Paris: PUF, 1998. Disponível em:<http://mafr.fr/media/assets/publications/catalap-ebauche-dune-theorie-juridiquede-linformation-1998.pdf>. Acesso em: 1 jun. 2018.

CONSELHO DA EUROPA. Carta dos Direitos Fundamentais da União Européia, de 18 de dezembro de 2000. Disponível em:< http://www.europarl.europa.eu/charter/pdf/text_pt.pdf>. Acesso em: 17 mai. 2018. 
CONSELHO DA EUROPA. Convenção de Estrasburgo para a proteção das pessoas relativamente ao tratamento automatizado de dados de caráter pessoal, de 1981.

Disponível em:<https://www.cnpd.pt/bin/legis/internacional/Convencao108.htm>. Acesso em: 1 jun. 2018.

DOTTI, René Ariel. A liberdade e o direito à intimidade. Revista de informação legislativa, v. 17, n. 66, p. 125-152, abr./jun., 1980.

ECHTERHOFF, Gisele. Direito à privacidade dos dados genéticos. Curitiba: Juruá, 2010.

FERRI, Luigi. L'autonomia privata. Milano: Giuffrè, 1959.

GEDIEL, José Antônio Peres. Autonomia do sujeito e biopoder. In: RAMOS, Carmen Lucia Silveira (Coord.). Diálogos sobre direito civil. Rio de Janeiro: Renovar, 2002.

. Tecnociência, dissociação e patrimonialização jurídica do corpo humano. In: $\overline{\mathrm{FACHIN}}$, Luiz Edson (Coord.). Repensando fundamentos do direito civil brasileiro contemporâneo. Rio de Janeiro: Renovar, 2000.

JABUR, Gilberto Haddad. A dignidade e o rompimento da privacidade. In: MARTINS, Ives Gandra da Silva; PEREIRA JúNIOR, Antonio Jorge (Coords.). Direito à privacidade. São Paulo: Idéias e Letras, 2005.

LEONARDI, Marcel . Tutela e privacidade na internet. São Paulo: Saraiva, 2009.

LÉVY, Pierre. O que é o virtual. Rio de Janeiro: Editora 34, 1996.

LUDWIG, Marcos de Campos. Direito público e direito privado: a superação da dicotomia. In: MARTINS-COSTA, Judith (org.). A reconstrução do direito privado. São Paulo: RT, 2002.

. O direito ao livre desenvolvimento da personalidade na Alemanha e possibilidade de sua aplicação no direito privado brasileiro. In: MARTINS-COSTA, Judith (org.). A reconstrução do direito privado. São Paulo: RT, 2002.

MARTINS, Leonardo (Org). 50 anos de jurisprudência do tribunal constitucional federal alemão. Montevideo: Konrad-Adenauer- Stiftung, 2005.

MEIRELLES, Jussara. O ser e o ter na codificação civil brasileira: do sujeito virtual à clausura patrimonial. In: FACHIN, Luiz Edson (Coord.). Repensando fundamentos do direito civil brasileiro contemporâneo. Rio de Janeiro: Renovar, 2000. 
MIRANDA, Felipe Arady. O direito fundamental ao livre desenvolvimento da personalidade. Revista do Instituto do Direito Brasileiro, Lisboa, ano 2, n. 10, 2013.

MIRANDA, Pontes de. Tratado de direito privado. Campinas: Bookseller, 1999.

MOUREIRA, Diogo Luna. Pessoas e autonomia privada: dimensões reflexivas da racionalidade e dimensões operacionais da pessoa a partir da teoria do direito privado. Rio de Janeiro: Lumen Juris, 2001.

NAVES, Bruno Torquato de Oliveira. 0 direito pela perspectiva da autonomia privada: relação jurídica, situações jurídicas e teoria do fato jurídico na segunda modernidade. 2. ed. Belo Horizonte: Arraes, 2014.

PERLINGIERI, Pietro. O direito civil na legalidade constitucional. Rio de Janeiro: Renovar, 2008.

RAMOS, Carmem Lucia Silveira. A constitucionalização do direito privado e a sociedade sem fronteiras. In: FACHIN, Luiz Edson (Coord.). Repensando fundamentos do direito civil brasileiro contemporâneo. Rio de Janeiro: Renovar, 2000.

REINALDO FILHO, Demócrito. Privacidade na sociedade de informação. Recife: $2006 . \quad$ Disponível em: <https://repositorio.ufpe.br/bitstream/123456789/4642/1/arquivo6028_1.pdf>. Acesso em: 6 jun. 2018.

RODOTÀ, Stefano. A vida na sociedade de vigilância: a privacidade hoje. Rio de Janeiro: Renovar, 2008.

RUZYK, Carlos Eduardo Pianovsk et. al. Direito civil constitucional: a ressignificação da função dos institutos fundamentais do direito civil constitucionais e suas consequências. Florianópolis: Conceito, 2014.

SAMPAIO, José Adércio Leite. Direito à intimidade e à vida privada: uma visão jurídica da sexualidade, da família, da comunicação e informações pessoais, da vida e da morte. Belo Horizonte: Del Rey, 1998.

SCHREIBER, Anderson. Direitos da personalidade. 2. ed. São Paulo: Atlas, 2013.

SILVA, Lucas Gonçalves da; CARVALHO, Mariana Amaral. Direito ao esquecimento na sociedade da informação: análise dos direitos fundamentais no meio ambiente digital. Revista Brasileira de Direitos e Garantias Fundamentais, v. 3, n. 2, p. 6686, jul./dez., 2017. 
SOUZA, Maria Isabel de Azevedo. O princípio da exclusividade como nota distintiva do direito privado. In: MARTINS-COSTA, Judith (org.). A reconstrução do direito privado. São Paulo: RT, 2002.

STRENGER, Irineu. Da autonomia da vontade. 2. ed. São Paulo: LTr, 2000. 